\title{
UTILIZAÇÃo DE PROBIÓTICO, PREBIÓTICO E SIMBIÓTICO EM RAÇÕES DE LEITÕES AO DESMAME ${ }^{1}$
}

\author{
Probiotic, prebiotic and symbiotic in weanning piglets rations
}

\author{
Ana Lígia Sanches ${ }^{2}$, José Augusto de Freitas Lima ${ }^{3}$, Elias Tadeu Fialho ${ }^{3}$, Luis David Solis Murgas ${ }^{4}$, \\ Erin Caperuto de Almeida ${ }^{5}$, José Vieira Neto ${ }^{5}$, Rilke Tadeu Fonseca de Freitas ${ }^{3}$
}

\begin{abstract}
RESUMO
Objetivou-se com este trabalho verificar o efeito da suplementação dietética de probiótico, prebiótico e simbiótico sobre o desempenho de leitões desmamados aos 23 dias de idade. Foram utilizados 96 leitões mestiços desmamados aos 23 dias de idade, com peso médio de 7,40 kg, utilizando-se um delineamento em blocos casualizados com quatro tratamentos, seis repetições e quatro leitões por unidade experimental, para se avaliar o desempenho durante o período de 35 dias. As dietas foram isoprotéicas e isoenergéticas, formuladas à base de milho, farelo de soja e leite em pó modificado, adicionadas de: antibiótico, probiótico, prebiótico ou simbiótico. As dietas foram formuladas para atender as exigências dos leitões segundo NRC (1998). Observou-se que os aditivos testados não influenciaram $(\mathrm{P}>0,05)$ o ganho de peso, consumo de ração e conversão alimentar. Conclui-se que a inclusão de probiótico, prebiótico ou simbiótico na alimentação de leitões desmamados aos 23 dias de idade proporcionou desempenho semelhante ao obtido com antibiótico.
\end{abstract}

Termos para indexação: Probiótico, Prebiótico, Simbiótico, Leitões, Desempenho.

\begin{abstract}
The objective of this study was to evaluate the effect of probiotic, prebiotic and symbiotic on the growth performance in the weanning piglets with 23 days old. A total of 96 weaned at 23 days old piglets, with the initial weight of $7.40 \mathrm{~kg}$ were distributed in a randomized block design with four treatments with six replicates and four pigs for experimental unit, to evaluate the performance during the period of 35 days. The diets were formulated based on corn and soybean meal, modified dried milk, isoproteic and isocaloric to meet the nutritional needs of the piglets accord to NRC (1998). The 4 treatments were based on: addition of antibiotic; probiotic, prebiotic and synbiotic as additive in the rations. It was observed that the tested additives had no influence $(\mathrm{P}>0.05)$ on the weight gain, feed intake and feed conversion over all experimental period. In conclusion the addition of probiotic, prebiotic or symbiotic in the piglets rations weanning at 23 days old shown similar action to those obtained with antibiotic.
\end{abstract}

Index terms: Probiotic, Prebiotic, Synbiotic, Piglets, Performance.

(Recebido para publicação em 26 de julho de 2004 e aprovado em 04 de março de 2005)

\section{INTRODUÇÃO}

O desmame precoce constitui uma prática muito importante na produção de suínos, principalmente levandose em consideração o fato de que a empresa suinícola visa o maior número de leitões desmamados/porca/ano, o que significa máxima produtividade.

De acordo com Mahan (1991), o período inicial após o desmame tem se caracterizado por redução no desempenho dos animais. Fatores como a idade e peso ao desmame, estresse, baixo consumo de alimento, composição da dieta, imaturidade digestiva e fatores ambientais, estão incluídos entre as causas de redução do crescimento durante a $1^{\mathrm{a}}$ semana após o desmame.
Durante muitas décadas têm-se utilizado antibióticos em doses subterapêuticas na nutrição dos leitões, visando reduzir os efeitos negativos da desmama precoce, porém a utilização desses antibióticos vem sendo banida, principalmente pela União Européia e outros países, pois os consumidores estão se preocupando com o fato de que os antibióticos podem promover o aparecimento de bactérias patogênicas multirresistentes a esses antibióticos e podem também, apresentar resíduos na carne e demais subprodutos animais.

A empresa suinícola nacional, desejando concorrer de forma participativa no mercado internacional, deve se adaptar a essa tendência de não utilização de antibióticos, ocasionando assim, uma forte demanda por produtos alternativos.

\footnotetext{
${ }^{1}$ Parte da dissertação de Mestrado do primeiro autor apresentada ao Programa de Pós-Graduação em Zootecnia da UFLA.

2 Zootecnista, M.Sc. pelo Departamento de Zootecnia da Universidade Federal de Lavras/UFLA - Cx. P. 3037 - $37200-000$ - Lavras, MG analigiasanches@yahoo.com.br

3 Professor do Departamento de Zootecnia da Universidade Federal de Lavras/UFLA - Cx. P. 3037 - $37200-000$ - Lavras, MG.

${ }^{4}$ Professor do Departamento de Medicina Veterinária da Universidade Federal de Lavras/UFLA - Cx. P. 3037 - $37200-000$ - Lavras, MG.

${ }^{5}$ Alunos de Mestrado em Zootecnia da Universidade Federal de Lavras/UFLA - Cx. P. 3037 - 37200-000 - Lavras, MG.
} 
Os aditivos utilizados nas rações constituídos por microorganismos vivos ou bactérias úteis foram denominados probióticos. De acordo com os relatos de Crawford (1979), probiótico pode ser definido como uma cultura de microorganismos vivos específicos, implantado no trato digestivo do animal através do alimento, garantindo o efetivo estabelecimento da população intestinal de microorganismos e assegurando a melhor utilização dos alimentos.

Segundo Gibson \& Roberfroid (1995), prebióticos são ingredientes nutricionais não digeríveis que afetam beneficamente o hospedeiro, estimulando seletivamente $o$ crescimento e a atividade de uma ou mais espécies de bactérias benéficas intestinais, melhorando a saúde do seu hospedeiro. Segundo Fernandes et al. (2003), os mananoligossacarídeos são carboidratos complexos contendo D-manose, derivados da parede celular de leveduras (Saccharomyces cerevisiae).

Segundo Menten (2002), o conceito de simbiótico alia o fornecimento de microorganismos probióticos juntamente com substâncias prebióticas específicas que estimulem seu desenvolvimento e atividade, potencializando o efeito de ambos os produtos.

Visou-se com o presente trabalho verificar o efeito da suplementação dietética de probiótico, prebiótico e simbiótico sobre o desempenho de leitões desmamados aos 23 dias de idade.

\section{MATERIAL E MÉTODOS}

O experimento foi conduzidos no Setor de Suinocultura do Departamento de Zootecnia da Universidade Federal de Lavras (UFLA), no período de outubro de 2002 a fevereiro de 2003. Foram utilizados 96 leitões mestiços (Landrace x Large White), desmamados, em média, aos 23 dias de idade, com peso médio de 7,40 kg $( \pm 1,05 \mathrm{~kg})$. Os leitões foram alojados na creche por um período de 35 dias, em grupos de quatro animais, sendo dois machos castrados e duas fêmeas, em baias suspensas (2,00 x 1,20 m), dotadas de comedouros semi-automáticos e bebedouros tipo chupeta em sala de alvenaria, com ambiente semi-controlado com lâmpadas e ventiladores. Antes de alojar os animais, a creche foi limpa e desinfetada, permanecendo por um período de sete dias em vazio sanitário.

Os animais foram distribuídos em um delineamento experimental de blocos casualizados com quatro tratamentos e seis repetições. Cada unidade experimental foi composta por quatro leitões. Os blocos foram formados para controlar as diferenças iniciais de peso.

As dietas experimentais foram: ração com antibiótico (Controle positivo), ração com probiótico, ração com prebiótico e ração com Simbiótico (Probiótico + Prebiótico). Os aditivos foram adicionados à dieta nas seguintes dosagens: Antibiótico (Olaquindox)-60 g por tonelada de ração; Probiótico (a base de Bacillus subtillis)-150 g por tonelada de ração; Prebiótico (mananoligossacarídeo)-1000 g por tonelada de ração e Simbiótico = Probiótico $(150$ g) + Prebiótico(1000 g)-1150 g por tonelada de ração.

As dietas foram isocalóricas e isoprotéicas, constituídas à base de milho, farelo de soja e leite em pó modificado, suplementadas com minerais e vitaminas. Foram formuladas para atender às exigências nutricionais dos leitões no período de creche, segundo NRC (1998). A composição percentual das rações encontra-se na Tabela 1.

As variáveis avaliadas foram: ganho de peso médio diário, consumo de ração médio diário e conversão alimentar. Para determinação do ganho de peso, os animais foram pesados aos 23 e 58 dias de idade (35 dias de experimento). As sobras de rações e o desperdício foram pesados semanalmente para determinação do consumo.

A análise estatística foi realizada através de análise de variância, utilizando-se o Sistema de Análise Estatística e Genética da Universidade Federal de Viçosa (SAEG, 1993).

\section{RESULTADOS E DISCUSSÃO}

Os resultados de ganho de peso médio diário (GPMD), consumo de ração médio diário (CRMD) e conversão alimentar (CA), são apresentados na Tabela 2.

Os dados de desempenho dos leitões alimentados com rações contendo probiótico, prebiótico e simbiótico não diferiram $(\mathrm{P}>0,05)$ daqueles alimentados com ração contendo antibiótico.

Estes resultados estão de acordo com os obtidos por Santos (2002), o qual avaliou a utilização de manose e antibiótico promotor de crescimento para leitões. Mikkelsen et al. (2003) compararam a utilização de dois prebióticos distintos para leitões desmamados e não verificaram diferenças significativas sobre os dados de desempenho.

Este comportamento também foi observado por Santos (1998) quando comparou o fornecimento de antibiótico e probiótico à base de Lactobacillus sp. para leitões nas fases de aleitamento e creche.

Em contraste, Kosasa (1986) quando combinou a utilização de probiótico à base de Bacillus toyoi com antibióticos, verificou aumento no ganho de peso e eficiência alimentar em leitões desmamados. Brendemuhl \& Harvey (1999), fornecendo $0,2 \%$ de mananoligossacarídeo para leitões dos 10 aos $28 \mathrm{~kg}$, observaram maior ganho de peso médio diário e consumo de ração médio diário quando comparado com o fornecimento de $0,1 \%$ do prebiótico. 
TABELA 1 - Composição percentual das rações experimentais.

\begin{tabular}{|c|c|c|c|c|}
\hline \multirow{2}{*}{ Ingrediente (\%) } & \multicolumn{4}{|c|}{ Tratamentos } \\
\hline & Antibiótico & Probiótico & Prebiótico & Simbiótico \\
\hline Milho & 53,600 & 53,600 & 53,600 & 53,600 \\
\hline Farelo de soja & 32,685 & 32,685 & 32,685 & 32,685 \\
\hline Leite em pó modificado & 10,000 & 10,000 & 10,000 & 10,000 \\
\hline Fosfato bicálcico & 1,500 & 1,500 & 1,500 & 1,500 \\
\hline Calcário calcítico & 1,000 & 1,000 & 1,000 & 1,000 \\
\hline Óleo de soja & 0,600 & 0,600 & 0,600 & 0,600 \\
\hline Sal iodatado & 0,300 & 0,300 & 0,300 & 0,300 \\
\hline Caulim & 0,109 & 0,100 & 0,015 & - \\
\hline Antibiótico & 0,006 & - & - & - \\
\hline Probiótico & - & 0,015 & - & - \\
\hline Prebiótico & - & - & 0,100 & - \\
\hline Simbiótico & - & - & - & 0,115 \\
\hline Premix vitamínico $^{1}$ & 0,100 & 0,100 & 0,100 & 0,100 \\
\hline Premix mineral $^{2}$ & 0,100 & 0,100 & 0,100 & 0,100 \\
\hline Total & 100 & 100 & 100 & 100 \\
\hline \multicolumn{5}{|c|}{ Nível Nutricional calculado } \\
\hline Proteína bruta (\%) & 20,500 & 20,500 & 20,500 & 20,500 \\
\hline $\mathrm{ED}(\mathrm{kcal} / \mathrm{kg})$ & 3400 & 3400 & 3400 & 3400 \\
\hline $\mathrm{Ca}(\%)$ & 0,947 & 0,947 & 0,947 & 0,947 \\
\hline Fósforo disponível (\%) & 0,550 & 0,550 & 0,550 & 0,550 \\
\hline Lisina Total $(\%)$ & 1,204 & 1,204 & 1,204 & 1,204 \\
\hline Metionina + cistina $(\%)$ & 0,698 & 0,698 & 0,698 & 0,698 \\
\hline
\end{tabular}

1_ Vit. A (8.000.000 UI); Vit. D (1.200.000 UI); Vit. E (20.000 mg); Vit. K 3 (2500mg); Tiamina (1000mg); Riboflavina (4000mg); Vit $B_{12}$ (20mg); Niacina (25000mg); Ácido Pantotênico (10000mg); Biotina (50g); Ácido Fólico (600mg); Vit. C (50000mg); Antioxidante $(125 \mathrm{mg})$.

22- Zn (80000mg); Fe (70000mg); Mn (40000mg); Cu (20000mg); I (800mg); Co (500mg); Se (500mg); Veículo qsp (1000g).

TABELA 2 - Efeito dos aditivos sobre o ganho de peso médio diário (GPMD), consumo de ração médio diário (CRMD) e conversão alimentar (CA) de leitões dos 23 aos 58 dias de idade ${ }^{1}$.

\begin{tabular}{lccc}
\hline \multirow{2}{*}{ Tratamento } & \multicolumn{3}{c}{ Variável } \\
\cline { 2 - 4 } & GPMD $(\mathbf{k g})$ & CRMD $(\mathbf{k g})$ & CA \\
\hline Antibiótico & 0,353 & 0,624 & 1,79 \\
Probiótico & 0,311 & 0,607 & 1,96 \\
Prebiótico & 0,352 & 0,635 & 1,81 \\
Simbiótico & 0,320 & 0,556 & 1,75 \\
\hline \multicolumn{1}{c}{ C.V.(\%) } & 13,17 & 10,07 & 8,83 \\
\hline
\end{tabular}

${ }^{1}$ Não houve diferença $(\mathrm{P}>0,05)$ pelo teste $\mathrm{F}$.

Ciênc. agrotec., Lavras, v. 30, n. 4, p. 774-777, jul./ago., 2006 
Como a eficácia dos produtos é estritamente dependente da quantidade e das características dos aditivos, é muito difícil estabelecer um paralelo entre estudos e comparar resultados.

$\mathrm{O}$ fato de os animais alimentados com rações suplementadas com os aditivos probiótico, prebiótico e simbiótico não terem apresentado diferenças significativas no desempenho, em comparação com os alimentados com antibiótico, demonstrou que é viável a utilização desses aditivos para evitar a utilização de antibióticos, mantendose o mesmo padrão de desempenho animal.

\section{CONCLUSÃO}

A inclusão de probiótico, prebiótico ou simbiótico na alimentação de leitões desmamados aos 23 dias de idade proporcionou desempenho semelhante ao obtido com antibiótico.

\section{REFERÊNCIAS BIBLIOGRÁFICAS}

BRENDEMUHL, J. H.; HARVEY, M. R. Evaluation of BioMos (Mananoligosaccharide) in diets for pigs: I. growth performance response during nursery and growingfinishing phases. Gainnesville: University of Florida, 1999. (Report to Alltech).

CRAWFORD, J. S. "Probiotics" in animal nutrition. In: ARKANSAS NUTRITION CONFERENCE, 1979, Arkansas. Proceedings... Arkansas: [s.n.], 1979. p. 45-55.

FERNANDES, P. C. C.; MALAGUIDO, A.; SILVA, A. V. Manejo nutricional visando substituir a utilização de antimicrobianos em alimentos para aves. In: SIMPÓSIO SOBRE MANEJO E NUTRIÇÃO DE AVES E SUÍNOS CBNA, 2003, Campinas, SP. Anais... Campinas: CBNA, 2003. p. 135-166.

GIBSON, G. R.; ROBERFROID, M. B. Dietary modulation of the human colonic microbiota: introducing the concepts of prebiotics. Journal Nutrition, Bethesda, v. 125, n. 6, p. 1401-1412, June 1995.

KOSASA, M. Toyocerin (Bacillus Toyoi) as growth promoter for animal feeding. Microbiology Alimentar Nutrition, [S.1.], v. 4, p. 121, 1986.

MAHAN, D. C. Efficacy of initial postweaning diet and supplemental coconut oil or soybean oil for weaning swine. Journal of Animal Science, Champaign, v. 69, n. 4, p. 1397 1402, Apr. 1991.

MENTEN, J. F. M. Probióticos, prebióticos e aditivos fitogênicos na nutrição de aves. In: SIMPÓSIO SOBRE INGREDIENTES NA ALIMENTAÇÃO ANIMAL, 2., 2002, Uberlândia, MG. Anais... Uberlândia: CBNA, 2002. p. 251-276.

MIKKELSEN, L. L.; JAKOBSEN, M.; JENSEN, B. B. Effects of dietary oligossaccharides on microbial diversity and fructo-oligossaccharide degrading bacteria in faeces of piglets post-weaning. Animal Feed Science and Tecnology, Amsterdam, v. 109, n. 1/4, p. 133-150, Oct. 2003.

NATIONAL RESEARCH COUNCIL. Nutrient requirements of swine: nutrient requirements tables. 10. ed. rev. Washington: National Academy, 1998. p. 110-123.

SAEG. Sistemas para análises estatísticas. versão 5.0. Viçosa: Fundação Arthur Bernardes, 1993.

SANTOS, M. S. Probiótico à base de Lactobacilos para leitões na fase de aleitamento e de creche. $1998.76 \mathrm{f}$. Dissertação (Mestrado em Tecnologia de Alimentos) Universidade Federal de Viçosa, Viçosa, 1998.

SANTOS, W. G. Manose na alimentação de leitões na fase de creche (Desempenho, parâmetros fisiológicos e microbiológicos). 2002. 66 p. Dissertação (Mestrado em Zootecnia) - Universidade Federal de Lavras, Lavras, 2002. 